\title{
The Use of the STAGS Finite Element Code in Stitched Structures Development
}

\author{
Dawn C. Jegley ${ }^{1}$ and Andrew E. Lovejoy ${ }^{2}$ \\ NASA Langley Research Center, Hampton, VA 23681
}

\begin{abstract}
In the last 30 years NASA has worked in collaboration with industry to develop enabling technologies needed to make aircraft more fuel-efficient and more affordable. The focus on the airframe has been to reduce weight, improve damage tolerance and better understand structural behavior under realistic flight and ground loading conditions. Stitched structure is a technology that can address the weight savings, cost reduction, and damage tolerance goals, but only if it is supported by accurate analytical techniques. Development of stitched technology began in the 1990's as a partnership between NASA and Boeing (McDonnell Douglas at the time) under the Advanced Composites Technology Program and has continued under various titles and programs and into the Environmentally Responsible Aviation Project today. These programs contained development efforts involving manufacturing development, design, detailed analysis, and testing. Each phase of development, from coupons to large aircraft components was supported by detailed analysis to prove that the behavior of these structures was well-understood and predictable. The Structural Analysis of General Shells (STAGS) computer code was a critical tool used in the development of many stitched structures. As a key developer of STAGS, Charles Rankin's contribution to the programs was quite significant. Key features of STAGS used in these analyses and discussed in this paper include its accurate nonlinear and post-buckling capabilities, its ability to predict damage growth, and the use of Lagrange constraints and follower forces.
\end{abstract}

\section{Introduction}

$\mathrm{I}$ n the last 30 years NASA has worked in collaboration with industry to develop enabling technologies needed to make aircraft more fuel-efficient and more affordable. The focus on the airframe has been to reduce weight, reduce manufacturing cost, improve damage tolerance and better understand structural behavior under realistic flight and ground loading conditions. Stitched structure is a technology that can address the weight savings, cost savings, and goals, but only if it is supported by accurate analytical techniques. Development of stitched technology began in the 1990's as a partnership between NASA and Boeing (McDonnell Douglas at the time) under the Advanced Composites Technology (ACT) Program ${ }^{1}$ and has continued under various titles and programs and into the Environmentally Responsible Aviation (ERA) Project ${ }^{2}$ today. These programs contained development efforts involving manufacturing development, design, detailed analysis, and testing. These programs started with selecting the material system and manufacturing approach, moved on to experimentation and analysis of small samples to characterize the system and quantify behavior in the presence of defects like damage and imperfections, then progressed to larger structures examining buckling behavior, combined loadings, and built-up structures, and finally moved to complicated subcomponents and full scale components. Each step along the way was supported by detailed analysis, to prove that the behavior of these structures was well-understood and predictable. This process of evaluating smaller specimens leading to larger structures is known as the building block approach and is shown in Fig. 1 where the steps are represented by photographs of test articles. Each experiment required a corresponding analysis, as represented in Fig. 2 showing a sampling of models of test articles. The Structural Analysis of General Shells (STAGS) computer code $^{3}$ was a critical tool used in the evaluation of all the structures shown here and others

\footnotetext{
${ }^{1}$ Senior Aerospace Engineer, Structures, Materials and Concepts Branch, Mail stop 190, Associate Fellow, AIAA.

${ }^{2}$ Senior Aerospace Engineer, Structures, Materials and Concepts Branch, Mail stop 190, Senior Member, AIAA.
} 


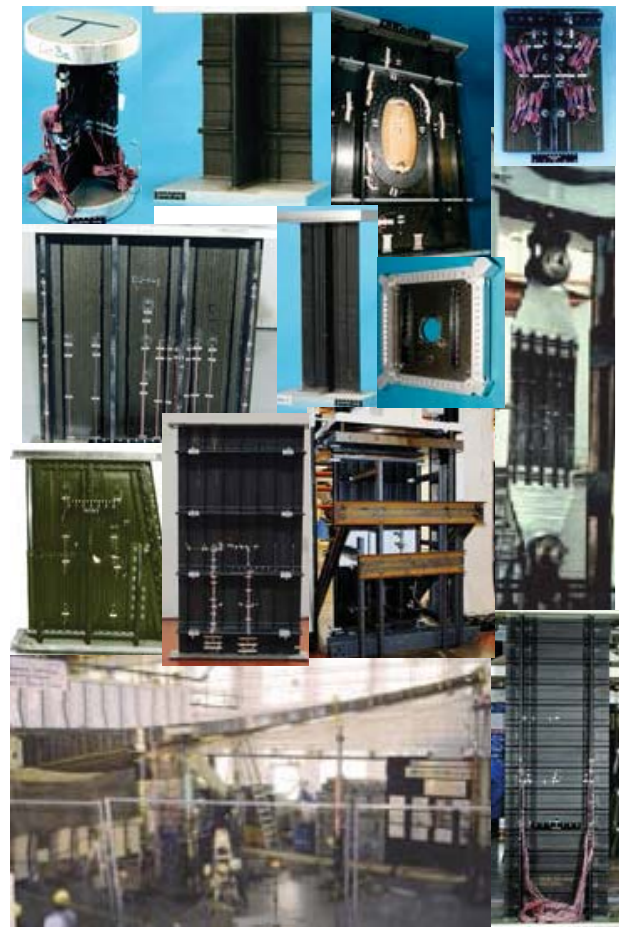

Figure 1. Stitched test articles.

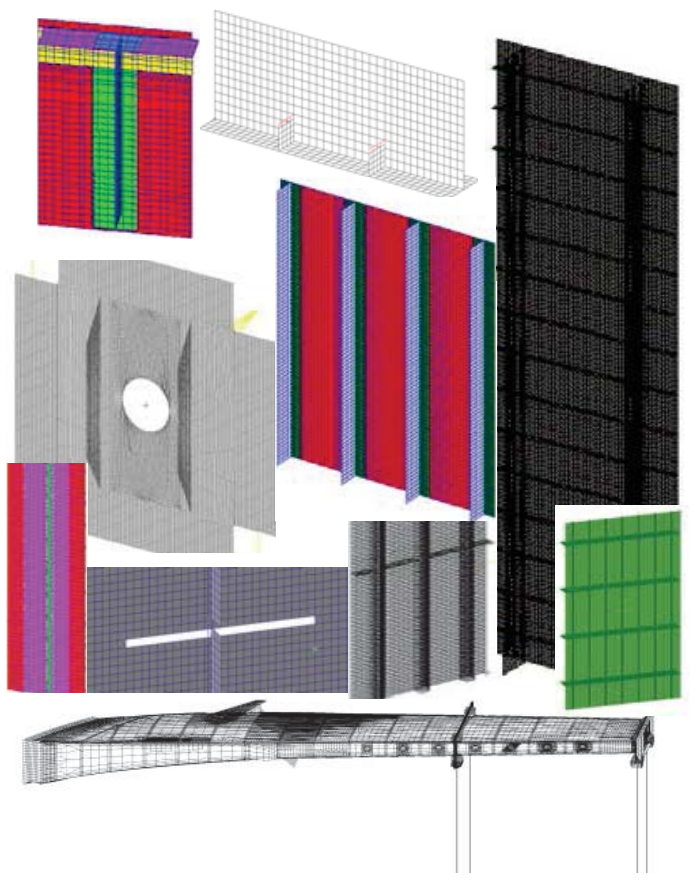

Figure 2. Finite element models.

described in references 4-20. The intent at each step in the process was to verify that the analytical results and the experimental data agreed because otherwise the behavior might not be adequately understood. As a key developer of STAGS, Charles Rankin's contribution to the programs was quite significant. This paper presents a discussion of the utilization of the STAGS computer code to analyze stitched structures from 1993 to 2013.

\section{Stitched Structure Programs}

In the ACT program, NASA and Boeing developed technologies applicable to the wing of a 220-passenger transport aircraft. The high stiffness and light weight of composite materials made composites the obvious choice. For the wing program, through-the-thickness stitching was selected to improve the damage tolerance of the wing by reducing damage growth and to reduce part count by eliminating the need for rivets by stitching the stiffeners to the skin. In addition to reducing part count, eliminating fasteners reduced the need for pad-ups since fastener holes were not needed, saving weight and reducing complexity. Eliminating fasteners also reduced cost by the cost of the fasteners themselves and the assembly time required for installation. In the ERA program, the technology developed under ACT are combined with improvements in out-of-autoclave processing, the development of single-sided stitching, the addition of a more structurally efficient stiffener, and more unitized structures are being applied to the pressurized center section of a hybrid wing body (HWB) aircraft. Stitching was the obvious solution to the challenges associated with the combination of in-plane loading and internal pressure on a nearly-flat panel found in the HWB center section. As shown in Figs. 1 and 2, STAGS was used to analyze small panels through to the 40-footlong wing test article in the ACT program. In the on-going ERA program, STAGS is used to analyze small singlestiffener specimens through larger panels, also shown in Figs. 1 and 2.

The stitching concept consists of carbon-epoxy panels fabricated from dry components, stitched, and then infused with resin. In ACT, a simple blade stiffener was used, while in ERA, a Pultruded Rod Stitched Efficient Unitized Structure (PRSEUS) concept is being used. In both blade-stiffened and PRSEUS concepts, skins, flanges, and stiffeners contain layers of graphite material forms made from Hercules, Inc. AS4 fibers that are prekitted in multi-ply stacks. Several stacks of the prekitted material are used to build up the desired thickness and configuration. The prekitted stacks have a $\left[45 /-45 / 0_{2} / 90 / 0_{2} /-45 / 45\right]_{\mathrm{T}}$ laminate stacking sequence resulting in an approximately [44/44/12] percent distribution of $0-, \pm 45-$, and 90 -degree plies. Nominal stack thickness was approximately 0.055 
inches for blade-stiffened panels and approximately 0.052 inches for PRSEUS panels. Any number of stacks can be assembled to obtain the desired thickness.

Blade-stiffeners were stitched with Kevlar threads and infused in an autoclave with 3501-6 resin using metal tooling to support the inner and outer moldlines (IML and OML, respectively). A sketch of the blade-stiffened cross section is shown in Fig. 3. Intercostals were positioned perpendicular to the blade-stiffeners and were composed of stacks of material and assembled in the same manner as the rod-stiffeners. PRSEUS panels are stitched together with Vectran threads and are infused in an oven using vacuum pressure with HexFlow VRM 34 resin and using hard metal OML tooling and inexpensive lightweight bags for IML tooling to enforce panel geometry. A PRSEUS structure includes a stiffener consisting of a thin web and a unidirectional carbon rod at the top of the web to provide structurally efficient stiffening in one direction while foam-filled frames are positioned perpendicular to the rodstiffeners to provide stiffening in the other direction. A sketch of the cross section of a PRSEUS rod-stiffened stiffener is shown in Fig. 4 and the intersection of the rod-stiffener and frame in the PRSEUS concept is shown in Fig. 5. The frames have two stacks of material wrapping around Rohacell $110 \mathrm{WF}$ foam. The rods are Toray unidirectional T800 fiber with a 3900-2B resin. Notice that the frames have small cutouts for the rod-stiffeners to pass through to provide an unbroken load path in the axial direction. Note that the number of stacks around the rod (overwrap stacks) is always half the number stacks in the rod-stiffener web. Similarly, the number of stacks in the flange is always half the number of stacks in the rod-stiffener web.

\section{Modeling and Analyzing Stitched Structures in STAGS}

The models of most of the stitched structures analyzed using the STAGS finite element code used primarily or exclusively shell elements and linear material properties. Typically stack properties are used rather than ply properties because coupon testing has determined that stitched stacks do not have the same properties as unstitched laminates since the stitching induces some fiber waviness. For most types of analyses, stack properties are adequate to determine global and local deformations, stresses and strains. However, to predict damage growth, individual ply properties are required. ${ }^{7.12,15,19}$ Unless considering damage growth, shell elements can be used to accurately predict the behavior of blade-stiffened panels. However, PRSEUS panels contain the pultruded rods, which are modeled as beam elements ${ }^{17,18,20}$ or as solid elements. ${ }^{19}$ In addition, the foam sandwich frame can be modeled as a standard layered shell elements ${ }^{17-20}$ or by using STAGS sandwich element. ${ }^{19}$ In addition, nonlinear material properties can be used as STAGS input. ${ }^{4}$

Geometrically nonlinear analysis is usually conducted for loading to the test specimen failure load or greater. Buckling analyses are typically conducted on compression-loaded specimens to determine the bifurcation buckling load and initial mode shape but nonlinear analysis is often required to determine how much load the structure will carry and quantify its post-buckling behavior since stitched structure has demonstrated an ability to support load beyond buckling. ${ }^{4,6,11-20}$ Nonlinear analysis can be conducted until collapse is reached and this result is compared to test data.

Analytical features which are used in STAGS include the ability to specify loads or applied displacements at which to provide calculated results while saving all information to restart the analysis, the ability to save time/space in computations by using a sparse matrix rather than a full matrix and the Riks method for calculating nonlinear results. STAGS also allows for Lagrange constraints and follower forces. ${ }^{10,14}$

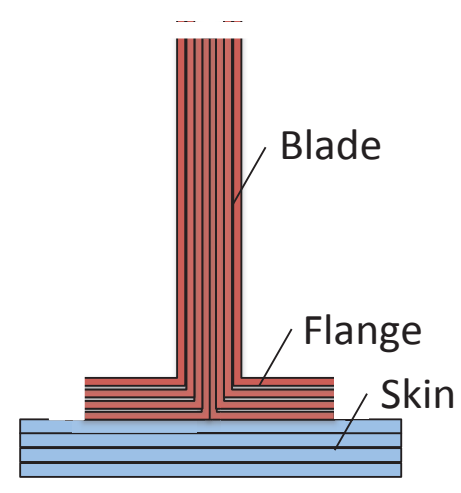

Figure 3. Cross section of blade stiffener.

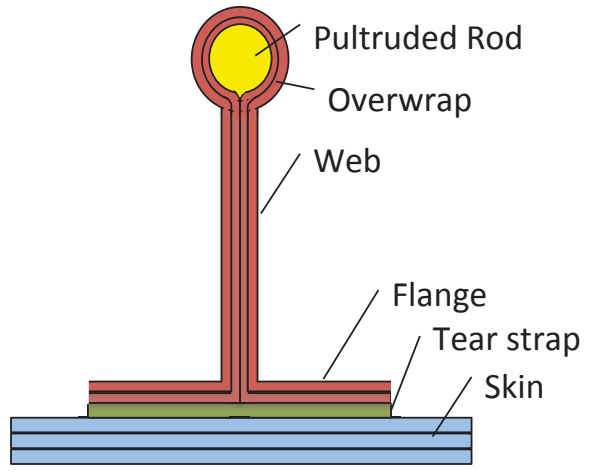

Figure 4. Cross section of PRSEUS rod stiffener. 


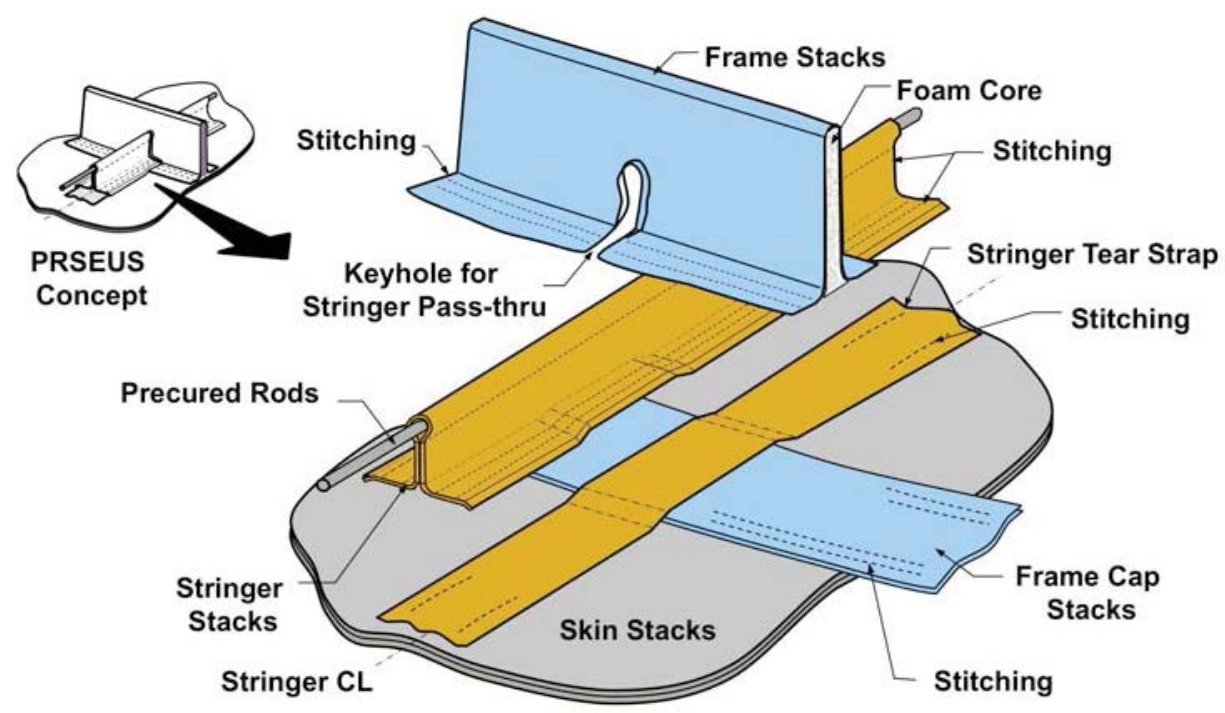

Figure 5. Exploded view of intersection of PRSEUS stiffeners.

None of the techniques or methodologies in STAGS were developed or implemented exclusively for stitched structure. But rather, the STAGS capabilities appropriate for layered composites were applied to stitched structure. Specifically, individual stitches were not modeled and delamination was not permitted. Since the presence of the stitches is accounted for in the in-plane material properties of the shell elements and pull-off forces that could drive delamination were evaluated by connecting flange nodes to skin nodes with beam elements where this force was considered important. Since experimentation has determined that the stitches are not the source of failures, the stitches and stitch strength is usually not considered in the analysis.

\section{Examples}

Three examples of STAGS analytical capabilities are described herein. Each example exploits one or more of the critical features in STAGS. For each example, structure is described and a comparison between STAGS results and experimental data is shown.

\section{A. Predicting Post-Bucking Behavior}

The ability to predict buckling, post-buckling and collapse behavior in skin-stiffener compression-loaded panels is critical to understanding their behavior. When the panel sustains local buckling prior to global buckling and prior to experiencing excessive strains, an analysis is required that will take into account large deformations and load redistribution. In many composite structures, local buckling leads to high out of plane forces between the skin and stiffener flanges, resulting in disbonding and structural failure. In stitched structure, the stitches prevent such disbonds, allowing the structure to reliably support repeated large deformations and high through-the-thickness forces so an analysis predicting behavior in the post-buckling regime is necessary to understand the enlarged design space that stitching offers.

However, numerical convergence issues often prevent finite element solvers from predicting behavior for loads greater than the initial buckling load. In many cases, these convergence difficulties can be overcome by giving the structure a small imperfection. In the studies cited herein, typically the imperfection shape is no more than a magnitude of $20 \%$ of the skin thickness, with a shape corresponding to the eigenvector of the minimum buckling load. This imperfection provides a trigger to overcome numerical difficulties and allow the analysis to progress into the post-buckling regime. STAGS allows the user to first calculate several eigenvectors, then restart the analysis and include one or more eigenvectors as imperfection shapes. Alternately, STAGS also allows the user to input assumed or measured imperfections through user written subroutines. 
The STAGS post-buckling capability was used on bladestiffened and PRSEUS panels., , $^{1,9,11-}$ 13,1-18,20 Examples of these specimens are shown in Fig. 6. The blade stiffened panel is representative of wing structure and the PRSEUS panel is representative of the center pressurized section of a HWB structure. Analytical and experimental results for the bladestiffened and PRSEUS specimens are shown in Figs. 7 and 8, respectively. For each case, displacements and strains are shown. Experimental data is shown by solid black lines. STAGS results are shown as dashed red lines. Symbols are used to distinguish between locations on the panel. Shortening and out-of-plane displacements are shown in Figs. 7a and 8a. Axial strains in the panel skins are shown in Figs. $7 \mathrm{~b}$ and $8 \mathrm{~b}$. In each case, results are linear until local buckling occurs in the skin. Displacements and strains indicate that the panels support load well into the postbuckling regime. Excellent correlation between the experimental results and the STAGS predictions was obtained.

\section{B. Damage progression analysis}

Typically a damage progression analysis is conducted with a nonlinear analysis where loads or deformations are slowly increased as failure is approached and through the failure of individual elements. The structure is first analyzed to determine the linear, nonlinear and buckling behavior using assumed properties for each stack of material to understand the behavior of the

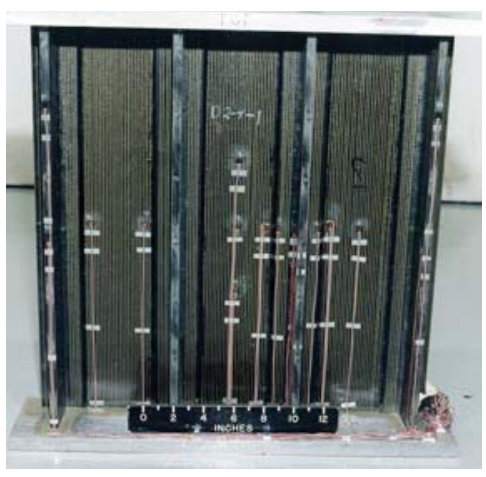

a) Blade-stiffened

$\begin{array}{ll}\text { a) Blade-stiffened } & \text { b) PRSEUS }\end{array}$

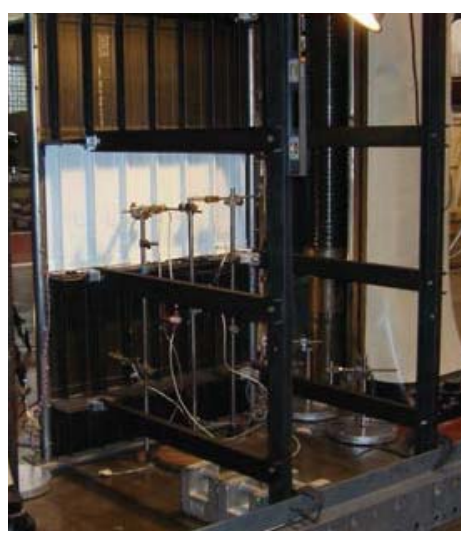

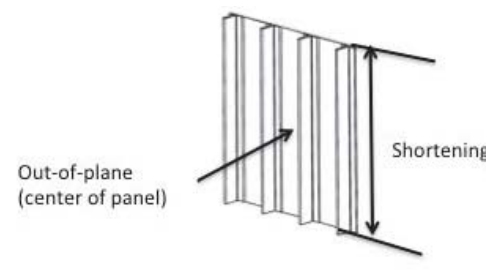
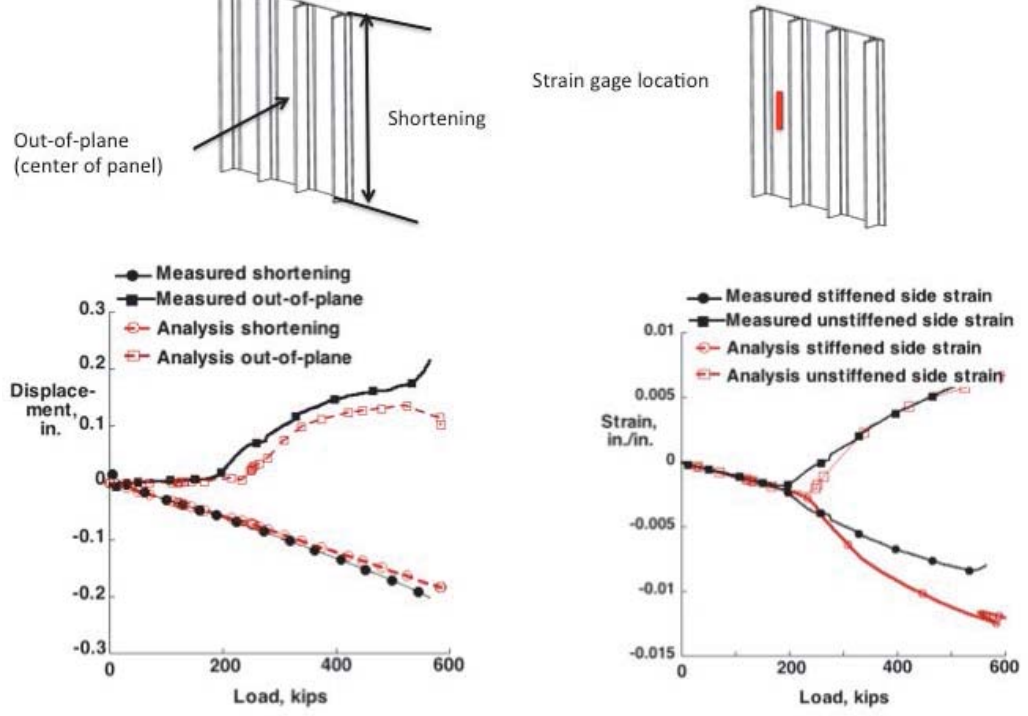

a) Displacements

b) Strains

Figure 7. Test and analysis results for blade-stiffened panel. structure and determine the strain distribution before any failure. Then a progressive failure analysis is conducted for the as-fabricated specimen to determine the load at which the first element would sustain damage and how the damage grows as elements begin to fail. Properties for each ply in each stack are used in the failure analysis. This failure prediction method in STAGS evaluates the strains and stresses in all plies in all elements and compares these values to the defined failure values. As the failure values are exceeded, appropriate ply level material properties are degraded and the ply loses its ability to carry load as the load to the structure is increased. Analytical results are obtained by examining the amount of damage and the location of damaged elements within the specimen at each load step. Each element in a model contains numerous locations where the stress and strain are calculated. The amount of damage in an element is expressed in terms of the percentage of these points that have stresses in excess of the input failure value. For stitched structures, delaminations between plies are not considered. 


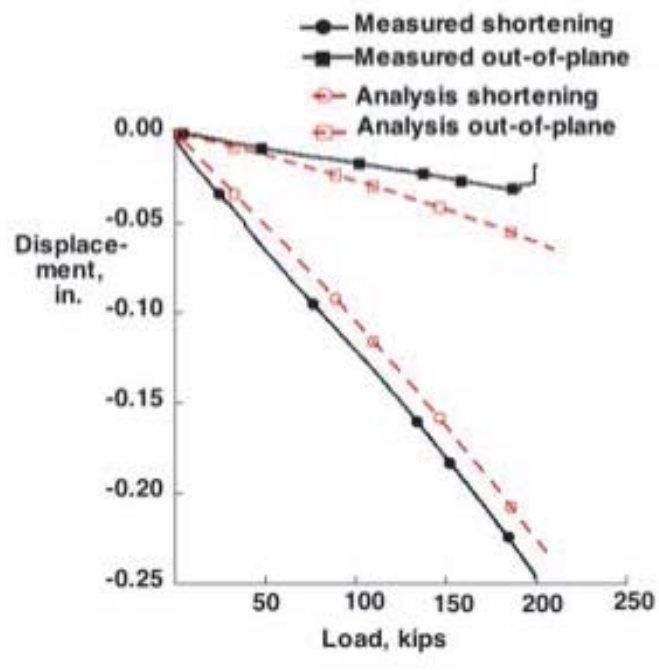

a) Displacements
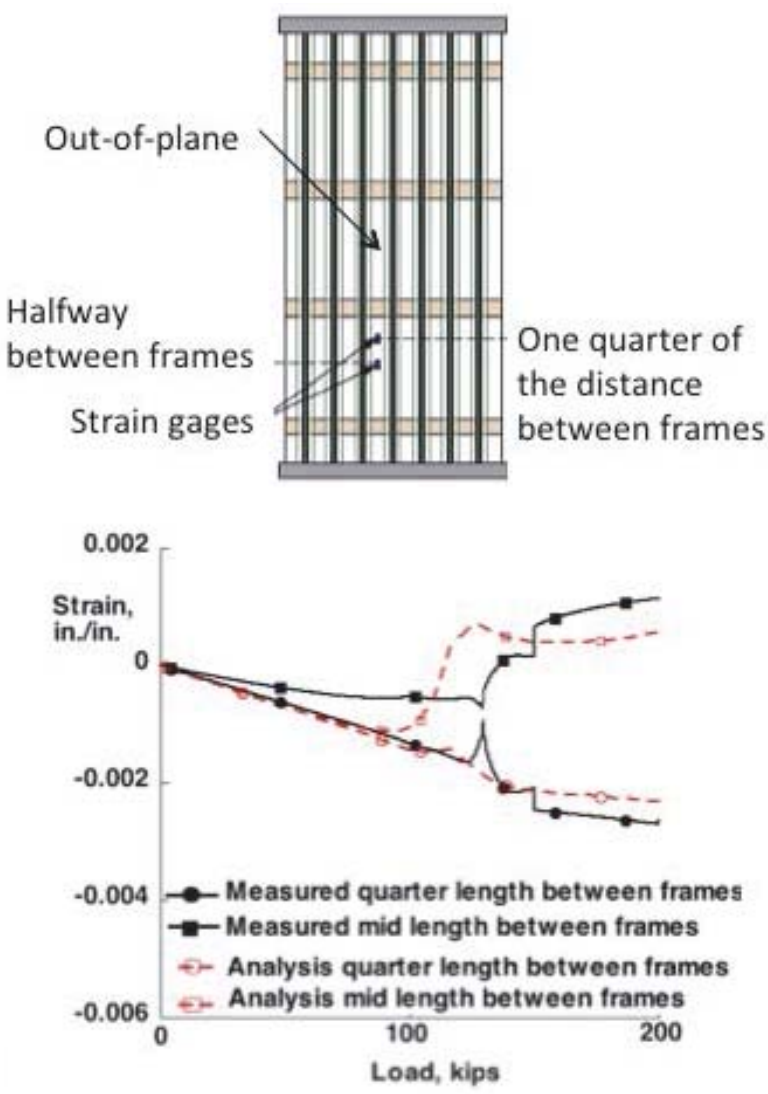

b) Strains

Figure 8. Test and analysis results for PRSEUS panel.

The STAGS damage progression methodology was used on blade-stiffened and PRSEUS crippling specimens. ${ }^{7,15,20}$ Examples of these specimens are shown in Fig. 9. Analytical and experimental results for the bladestiffened and PRSEUS specimens are shown in Figs. 10 - 14 and 15 - 19, respectively. For each case, displacements, strains and failures are shown. Shortening and out-of-plane deformations are shown in Figs. 10 and 15, with the dashed lines representing experimental data and the solid lines representing STAGS results. Point strains are shown in Figs. 11 and 16. Predicted full-field strains are shown in Figs. 12 and 17. The predicted location of the first failures are shown in Figs. 13 and 18 where the color of the element indicates how much damage it has sustained. Failed specimens are shown in Fig. 14 and 19. Excellent correlation between the experimental results and the STAGS predictions was obtained. Failure patterns are consistent with the locations of predicted initial failure and failure progression.

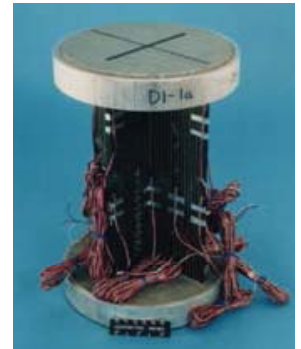

a) Blade-stiffened

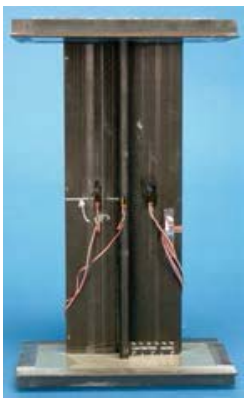

b) PRSEUS

Figure 9. Crippling specimens used with damage progression analysis. 


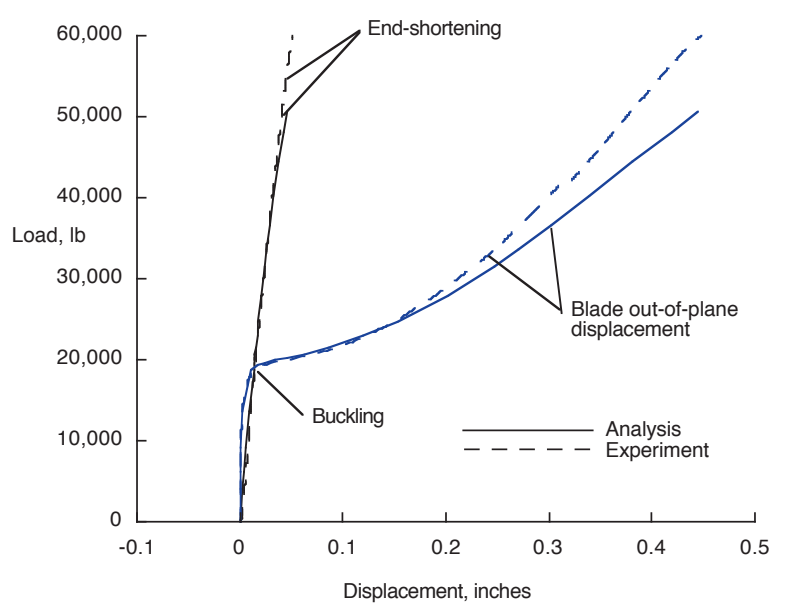

Figure 10. Blade-stiffened specimen displacements.

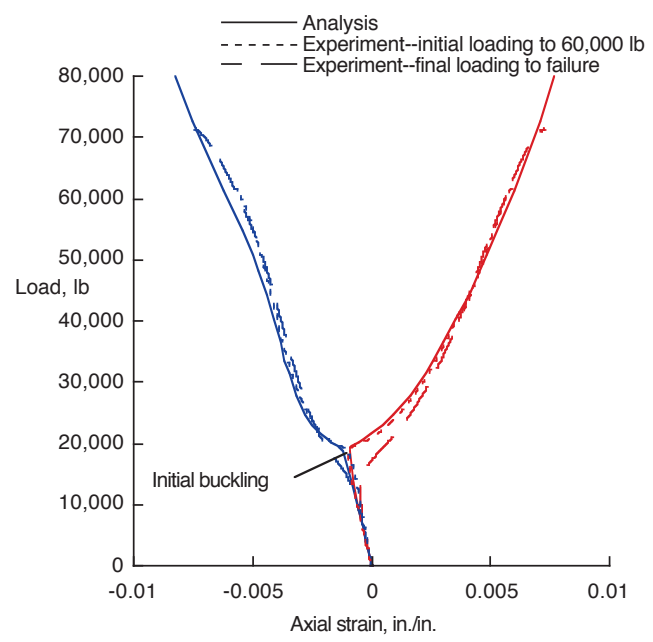

Figure 11. Blade-stiffened specimen strains at mid length.

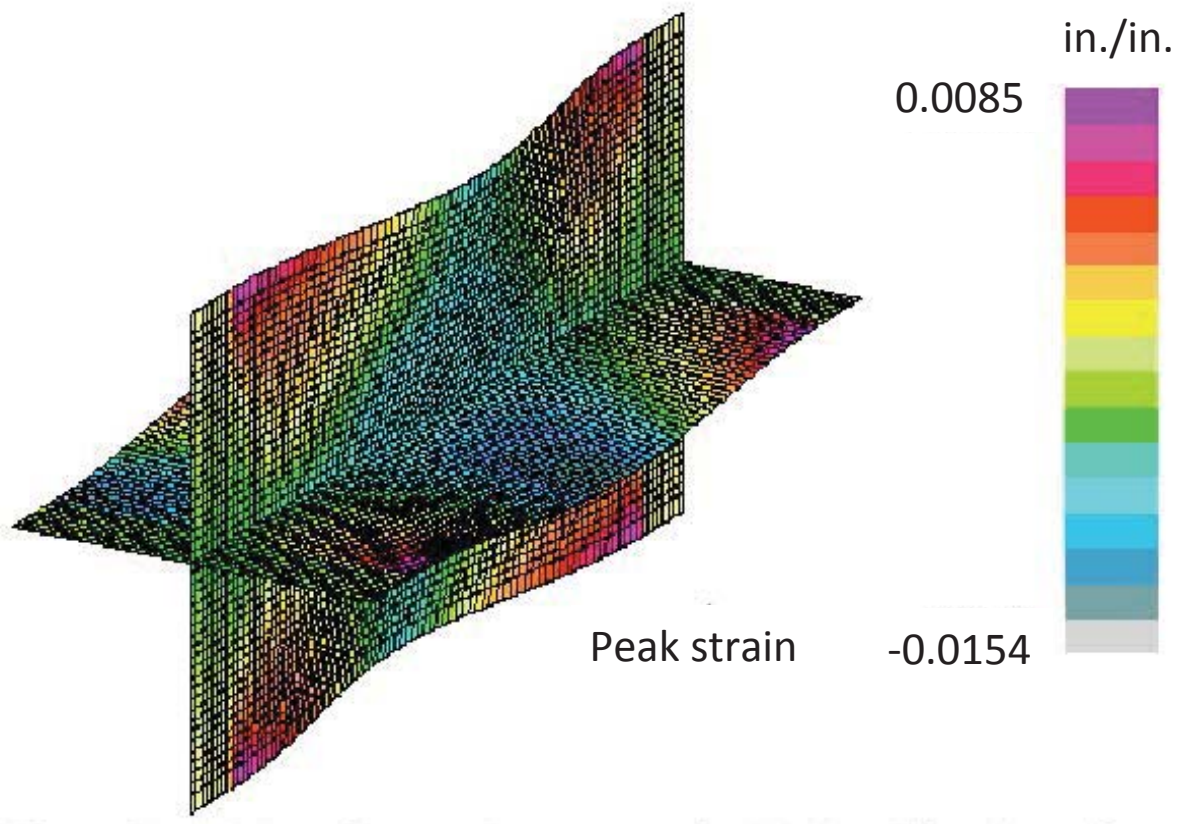

Figure 12. Blade-stiffened specimen strain at 72,000 lb. 


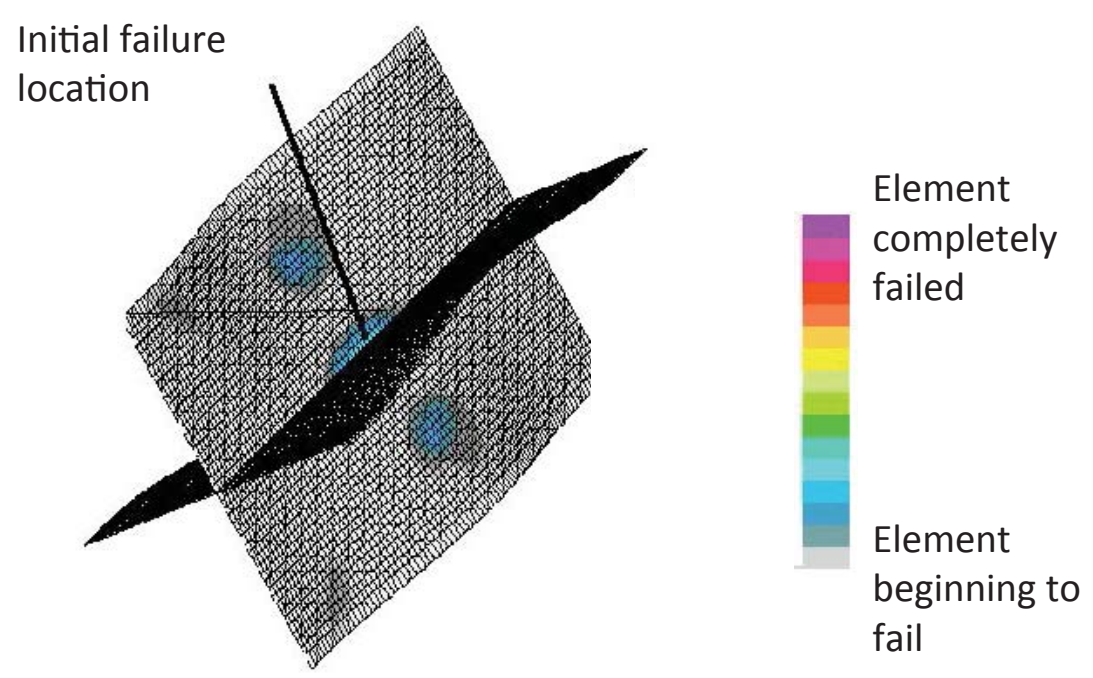

Figure 13. Damaged elements for an applied load of 2.7 times the buckling load for the blade stiffened specimen.

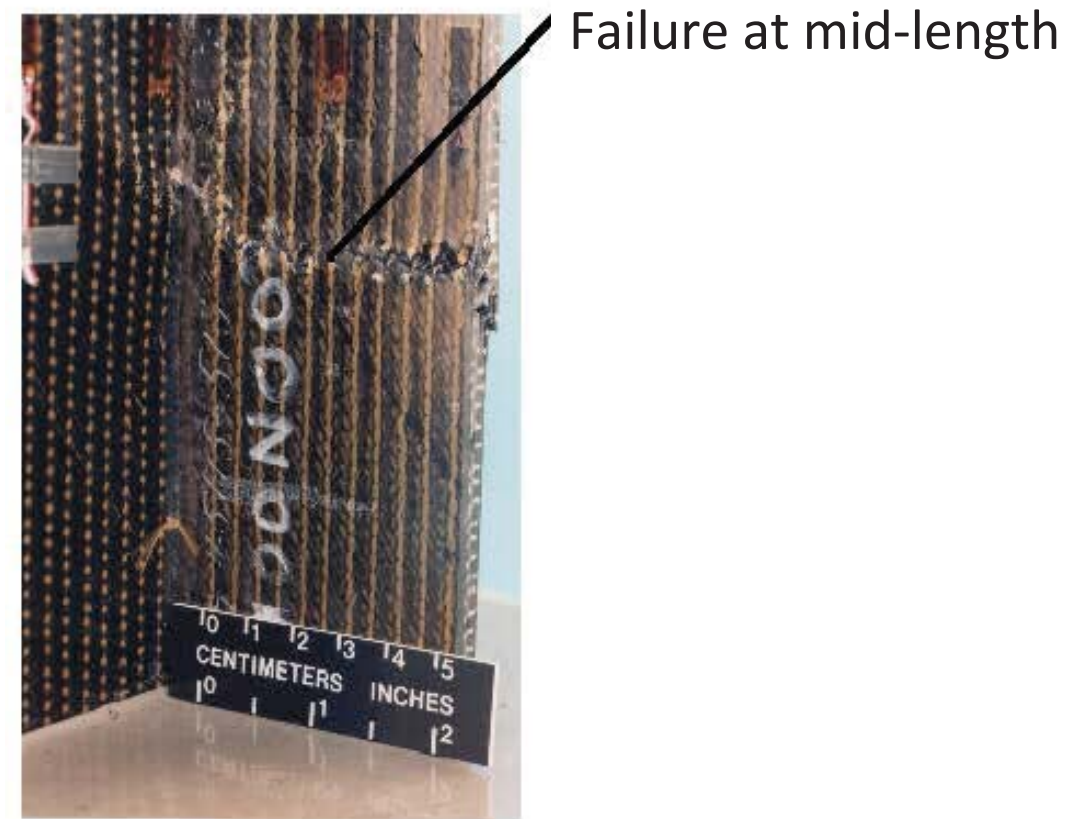

Figure 14. Failed blade-stiffened specimen. 


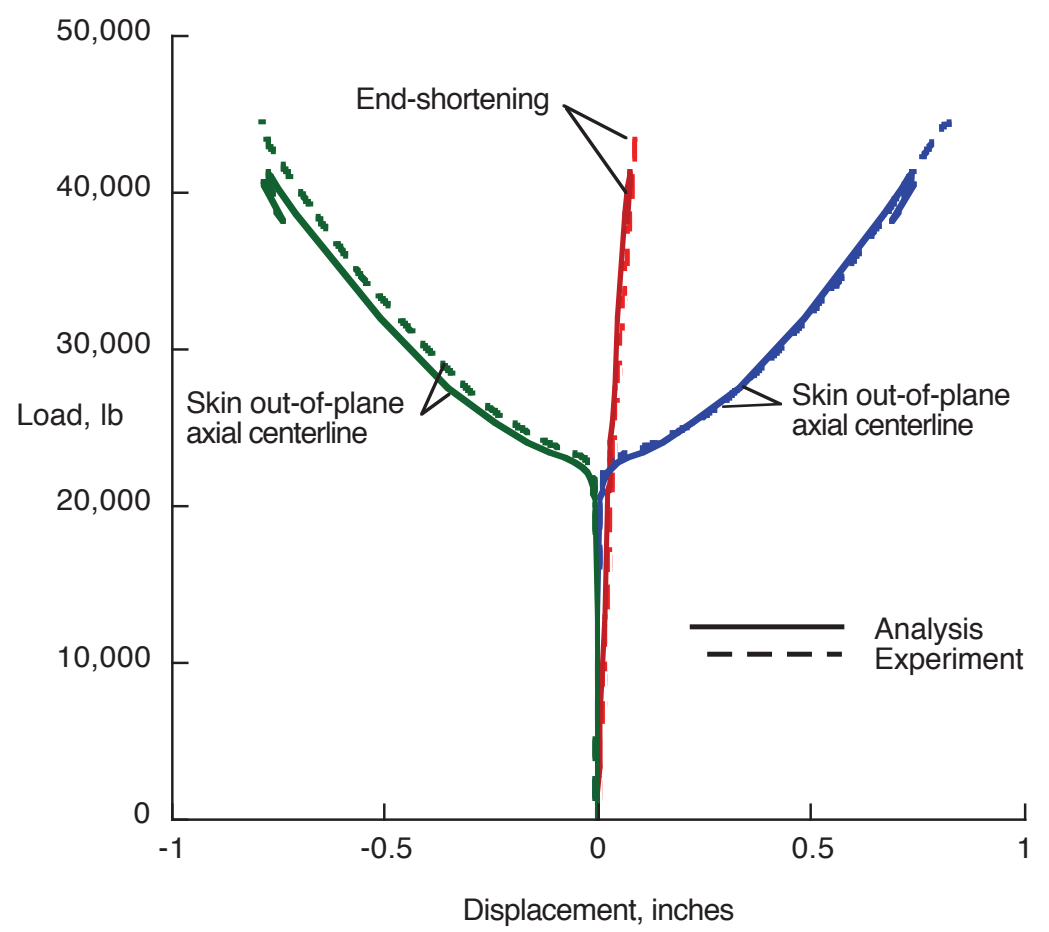

Figure 15. Displacements for PRSEUS crippling specimen.

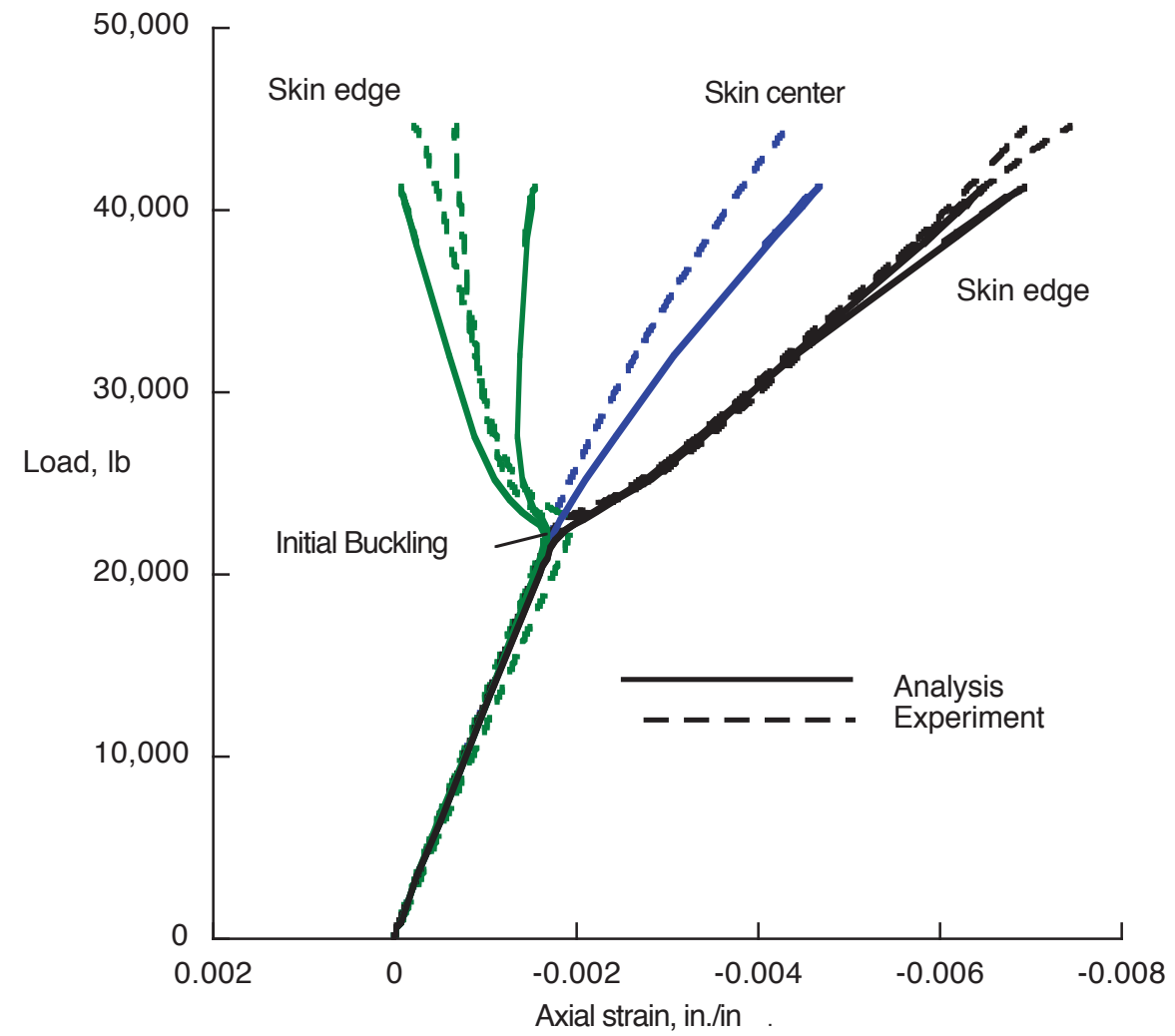

Figure 16. Axial strain for PRSEUS crippling specimen. 


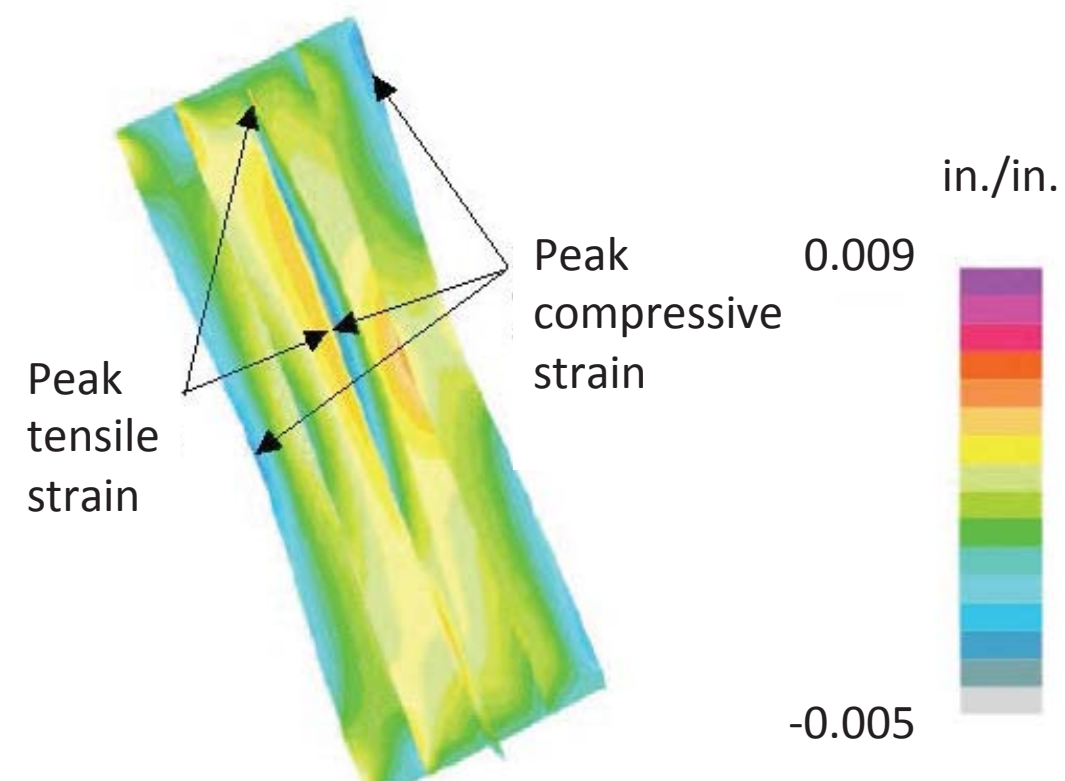

Figure 17. Full-field axial strain for PRSEUS crippling specimen at 38,831 lb.

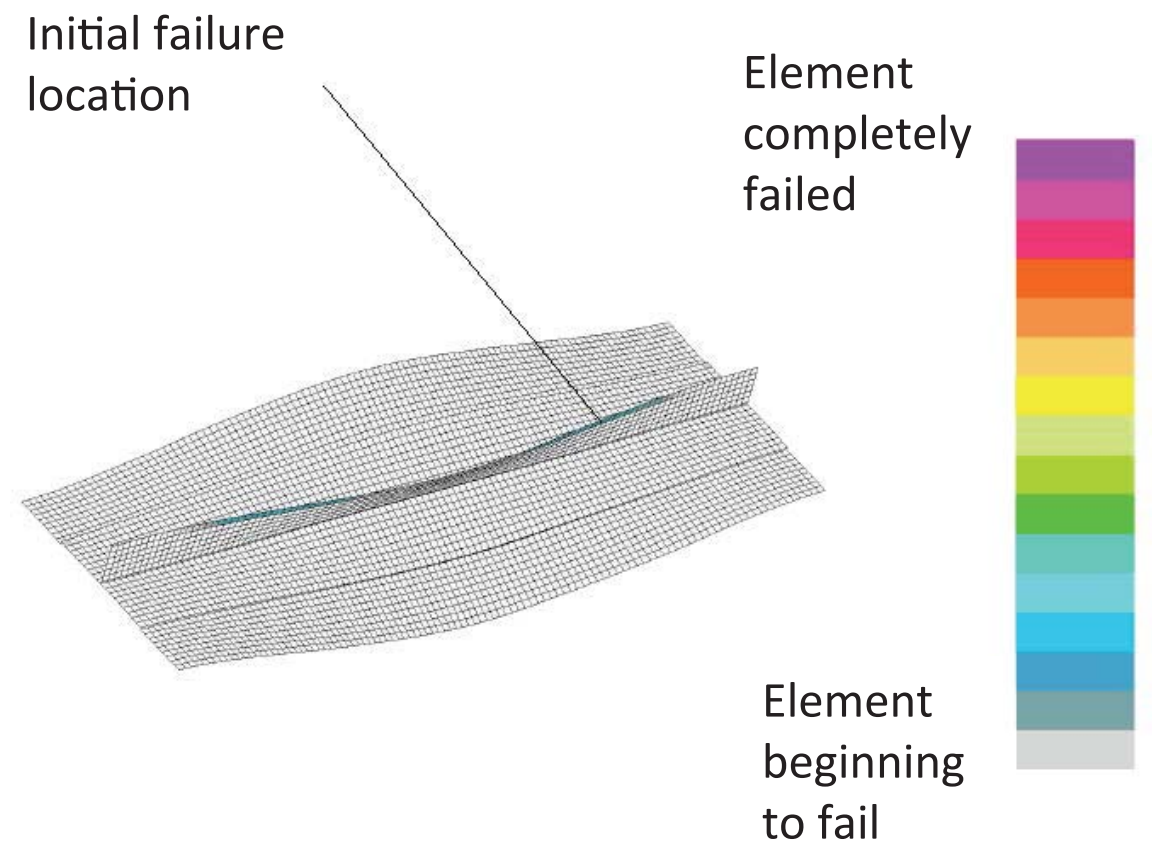

Figure 18. Failure prediction for PRSEUS crippling specimen loaded to 1.8 times the buckling load. 


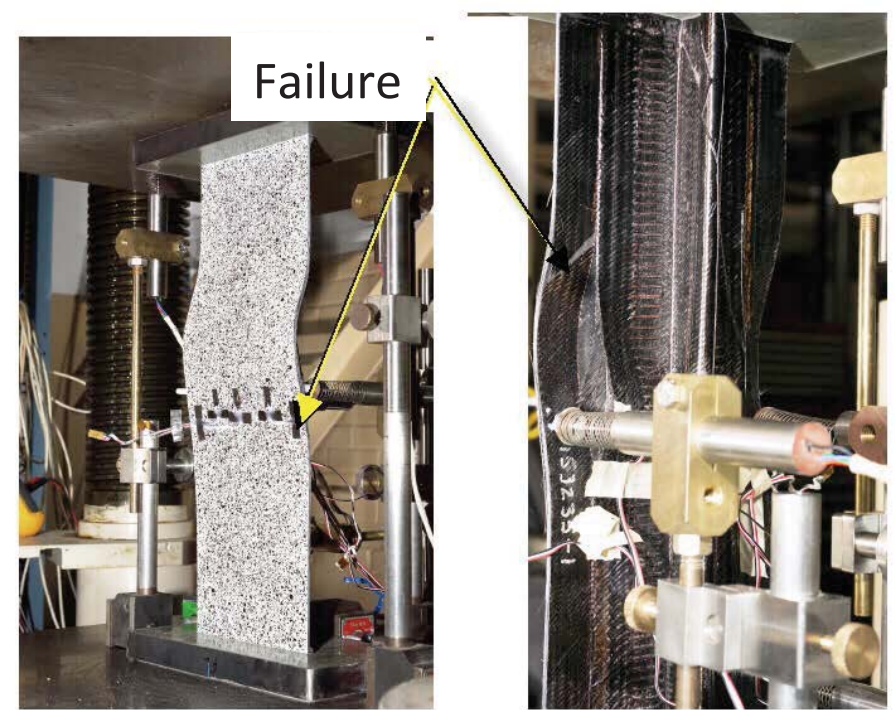

Figure 19. Failed PRSEUS crippling specimen.

\section{Semi-Span Wing}

As part of the ACT program, a composite semi-span test article representative of a 220-passenger aircraft wing box was analyzed and tested., 10,14 The full-scale test article, shown in Fig. 20, was the culmination of a series of structures made of stitched, blade-stiffened construction that were carried out at NASA and Boeing, and followed the successful analysis and testing of stitched, blade-stiffened subcomponent articles such as those previously described. The semi-span was subjected to three load cases, namely braked-roll, $2.5 \mathrm{G}$ up-bending and $1.0 \mathrm{G}$ down-bending. Loads were applied using four pairs of actuators along the semi-span length, and a ninth actuator attached to a load arm for the braked-roll load case. Initial analyses were conducted using MSC/NASTRAN. This initial finite element model was then converted to STAGS for pretest predictions and post-test correlation. Details of the STAGS analysis are presented in reference 10 .

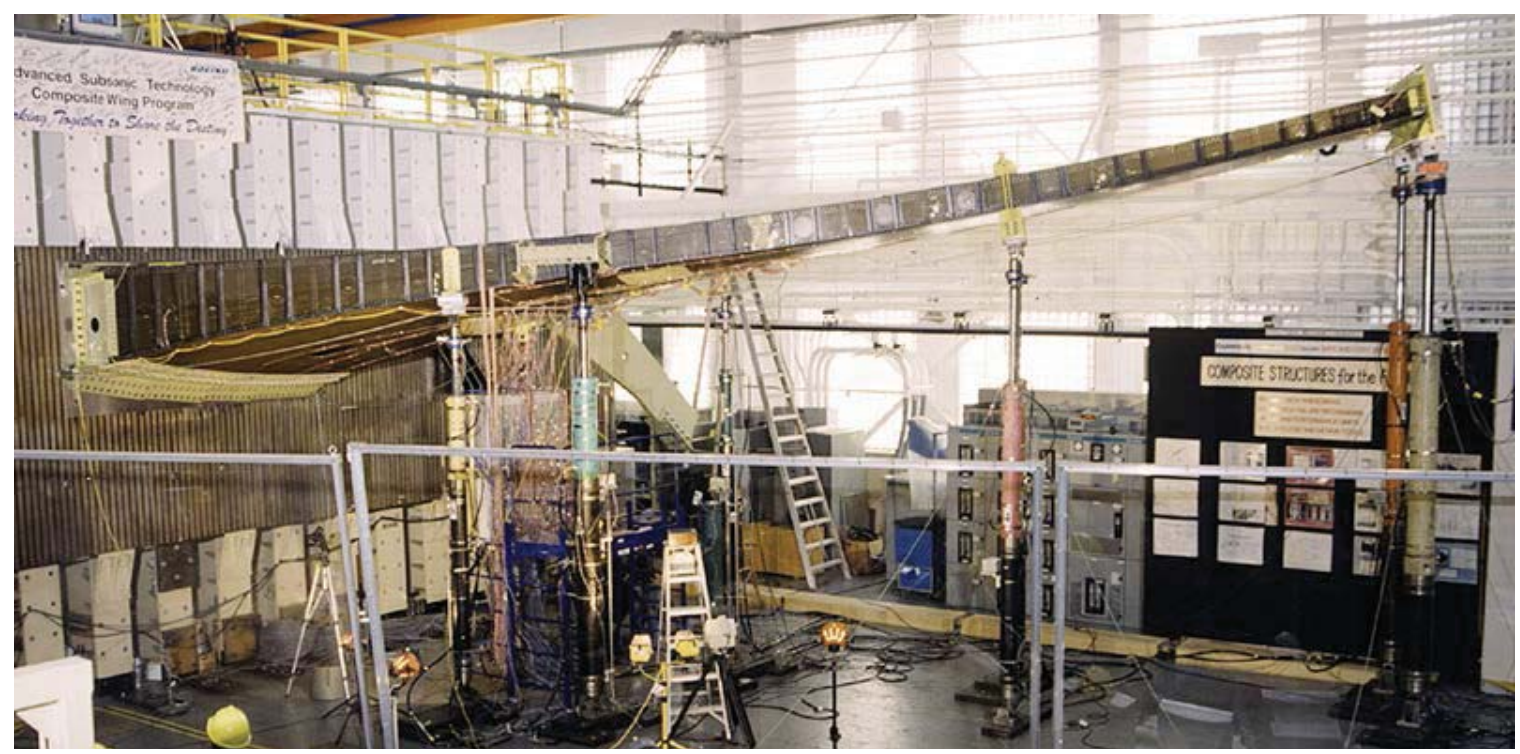

Figure 20. ACT stitched composite semi-span test article just prior to failure in the $2.5 \mathrm{G}$ up-bending condition. 
The STAGS model incorporated numerous details, including stringer runout tapers, spar web doublers, refinements in the vicinity of strain gages and damage locations, load introduction fixtures, and load introduction directional accuracy. More accurate modeling of the load introduction fixtures and changes in the relative orientation of the loading direction as the structure deformed than were included in the initial model was crucial to successful testing of the semi-span, as it identified two key issues associated with the load fixtures. Initial analyses of the semispan were accomplished by applying loads in the initial load actuator direction, or with follower loads. Deformation of the semi-span indicated that neither of these load application approaches were appropriate, particularly at the two outboard load application locations, and on the load arm used to apply the braked-roll load. To simulate the actuators in the analysis, beam elements were added to represent the actuators. The actuator elements were fixed at the ground end in all three translations, and in rotation about the axis of the beam to remove rigid body motion of the actuator beam elements. The ends of the actuator elements at the semi-span were connected to the load fixtures using STAGS Lagrange constraints, implemented using the G3 and G4 records. ${ }^{3}$ Use of these Lagrange constraints permits the user to effectively enforce the compatibility of the required degrees of freedom (translations in this case) at the actuator element/load fixture interface. This method of connection results in a follower force that is oriented along the axis of the actuator beam when the force is applied to the actuator element node. The semi-span finite element model (FEM) with outboard load introduction fixtures and actuator elements incorporated for the $-1.0 \mathrm{G}$ and $2.5 \mathrm{G}$ load cases is shown in Fig. 21.

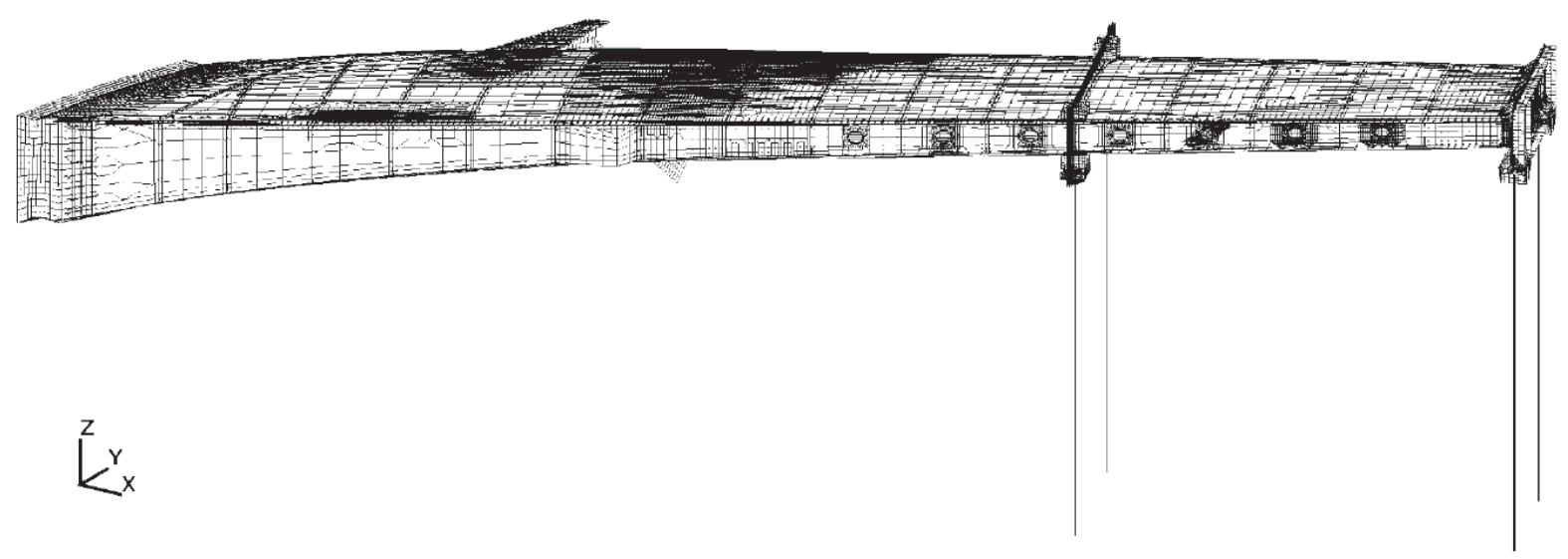

Figure 21. Semi-span FEM with outboard load introduction fixtures and actuators modeled.

The tip load introduction fixture shown in Fig. 21 initially consisted of a single flat plate. However, deflection of the tip under bending loads introduced an actuator force that did not remain in-plane with the flat plate, which introduced bending in the load introduction fixture. This bending resulted in bending stresses that exceeded the design allowables. Therefore, L-brackets were attached to the tip load introduction fixture (as seen in Fig. 21) to prevent fixture bending and to reduce stresses in the fixture to acceptable levels. Analytical and experimental displacements at the outer load points are shown in Fig. 22. Analytical results are represented by dashed red lines and experimental results are represented by solid black lines. Displacements at the two actuators at the wing tip are identified by circles and displacements at the next inboard load introduction point, at rib 13, are identified by squares. Very good agreement between test and analysis is seen.

Similarly, the flat load arm plate to which the braked roll actuator attached (identified in Fig. 23) began to bend out of plane as a result of the actuator load being applied eccentric to the load arm fixture I-beam web. To counteract this bending, during the braked roll load condition an additional actuator was attached to the backstop to which the root plates were mounted, and was actuated to keep the plate nearly planar. A comparison of the braked roll load arm plate displacements with and without the additional actuator is shown in Fig. 24. The maximum displacement can be seen to be reduced from approximately 3.5 inches to approximately 0.41 inches. The bending and torsion response initially exhibited by the load arm plate was drastically reduced by the introduction of the lateral actuator, which resulted in significantly reduced stresses.

Using the STAGS Lagrange constraint capability, coupled with follower loads, it was possible to analyze the stitched composite semi-span with the proper kinematics between the load actuators and the test article's load 
introduction fixtures. This approach permitted identification of high stresses in two load introduction fixtures, which were alleviated using additional structure at the tip fixture, and an additional actuator at the load arm plate. Such a capability to accurately analyze the kinematics of the test set-up was crucial to the analysis of the test conditions.

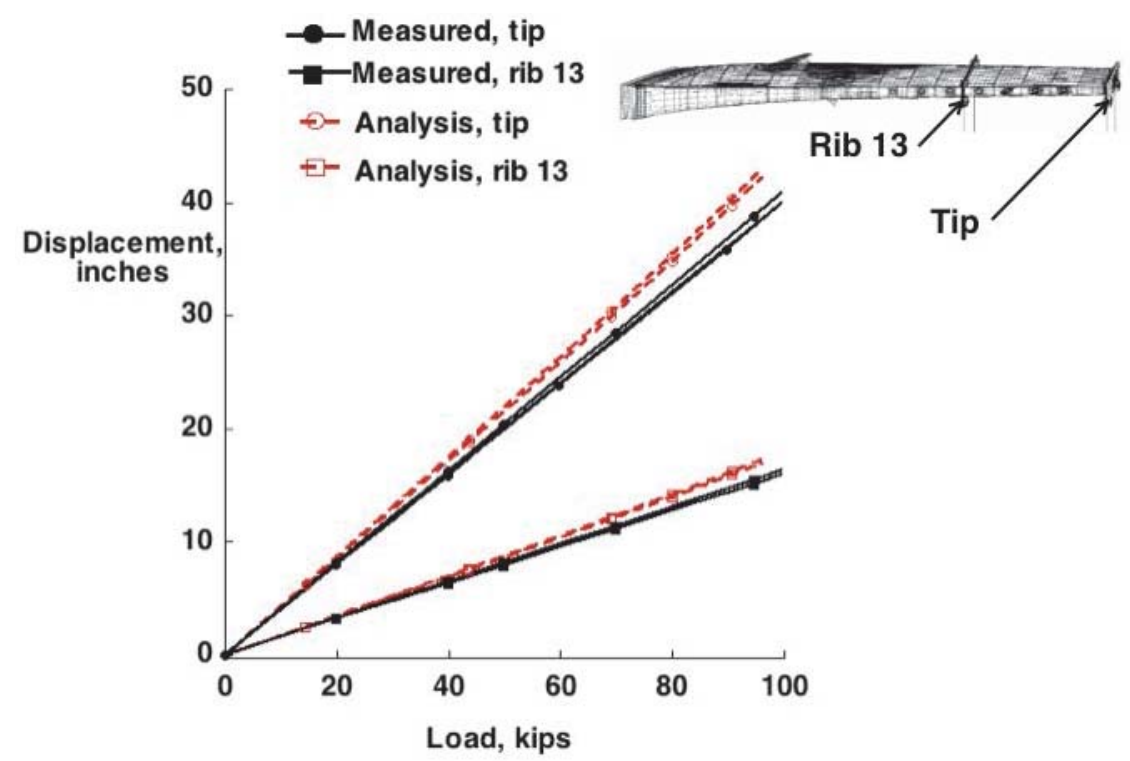

Figure 22. Semi-span displacements during final loading in 2.5G up-bending condition.

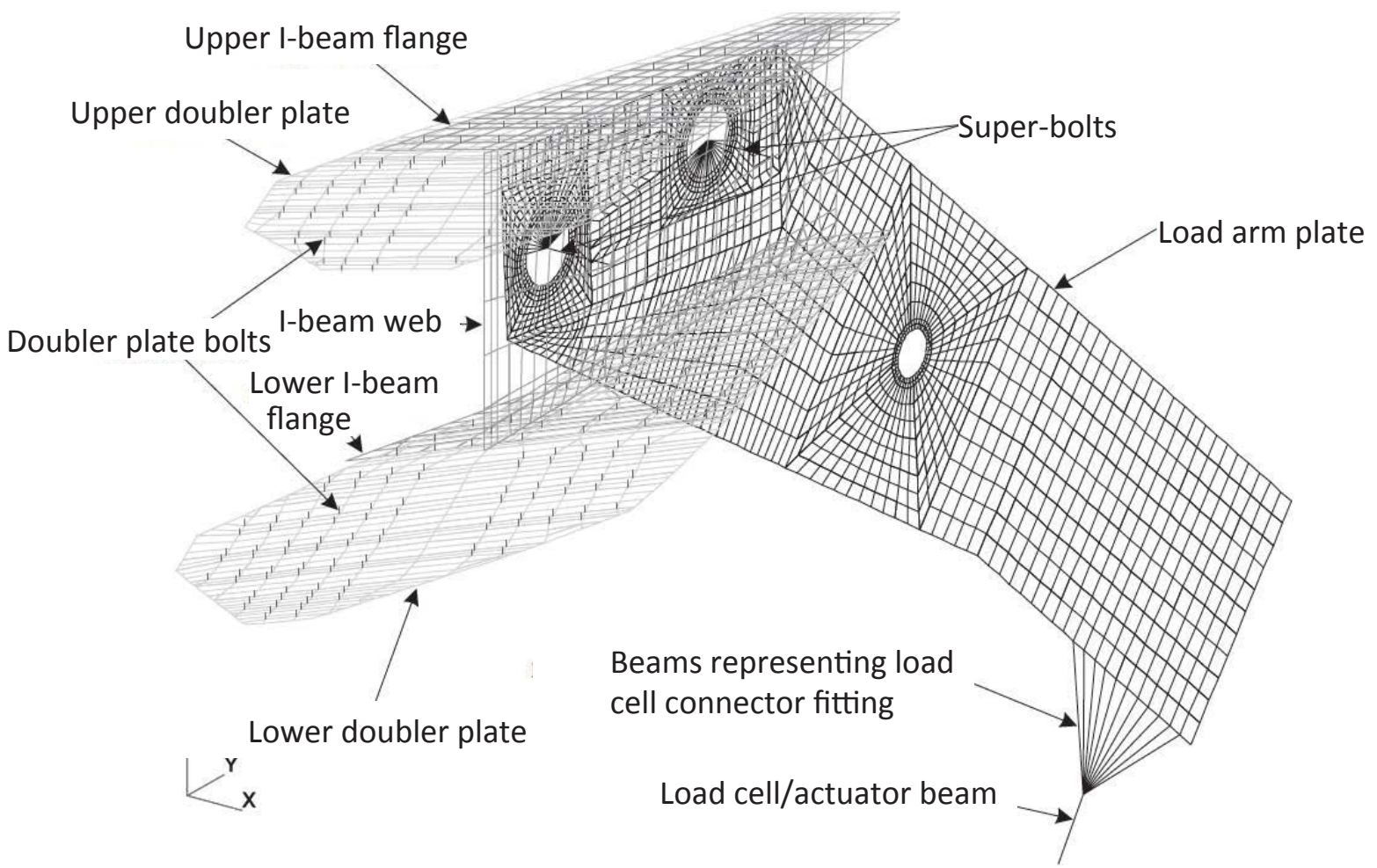

Figure 23. Load arm assembly FEM with components identified. 

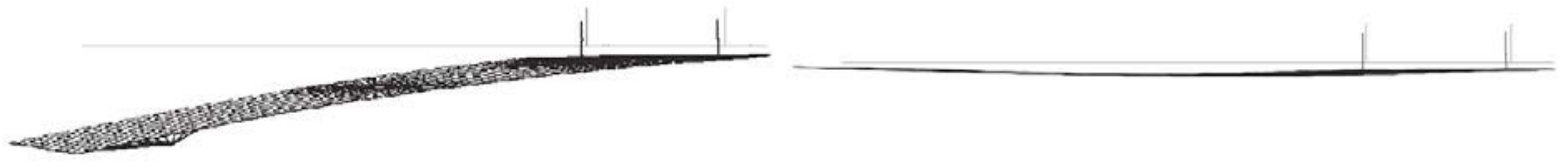

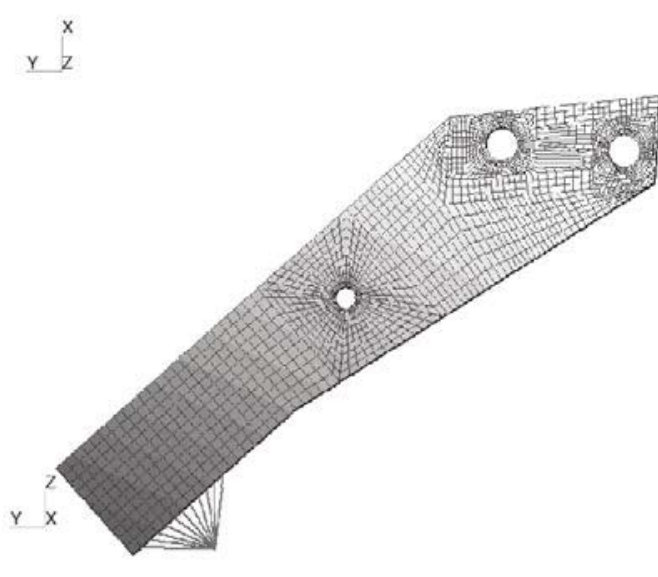

a) Follower load, no lateral actuator

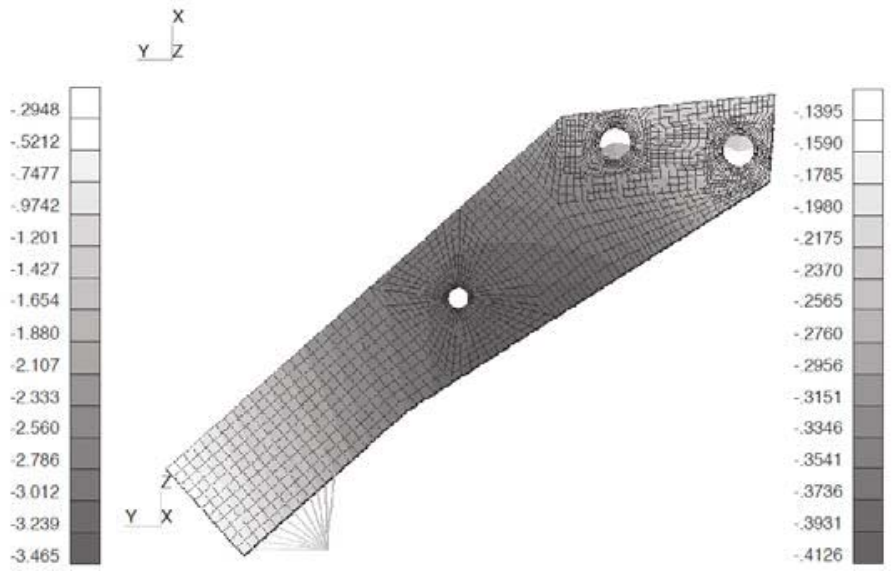

b) Follower load, with lateral actuator

Figure 24. Loadarm assembly deformation comparison. Scale is in inches.

\section{Concluding Remarks}

The STAGS computer code has been a valuable tool in the development of stitched structures over the last 20 years. Key features of STAGS used in these analyses and discussed in this paper include its accurate nonlinear and post-buckling capabilities, its ability to predict damage growth, and the use of Lagrange constraints and follower forces. Experimental results show that STAGS has accurately predicted structural behavior among numerous types of structures and under numerous loading conditions.

\section{References}

1. Karal, M., “AST Composite Wing Program - Executive Summary,” NASA CR 2001-210650.

2. Jegley, D. and Velicki, A., "Status of Advanced Stitched Unitized Aircraft Structures," Presented at the 51st AIAA Aerospace Sciences Meeting, Grapevine, TX, January 2013.

3. Rankin, C. C., Brogan, F. A., Loden, W. A., and Cabiness, H. D., "STAGS User Manual, Version 3.0," Lockheed Martin Missiles \& Space Co., Inc., Rept. LMSC P032594, March 1999.

4. Jegley, D. and Waters, W. Jr., "Test and Analysis of a Stitched RFI Graphite-Epoxy Panel with a Fuel Access Door," NASA TM 108992, March, 1994.

5. Sutton, J., Kropp, Y., Jegley, D., and Banister-Hendsbee, D., “Design, Analysis and Tests of Composite Primary Wing Structure Repairs,” Presented at the 5th ACT Conference, Seattle, Washington, August 1994. NASA CP 3294, Vol. 1, Pt 2, pp 879-912.

6. Hinrichs, S., Chen, V., Jegley, D., Dickinson, L., and Kedward, K., "Effect of Impact on Stitched/RFI Compression Panels," Presented at the 5th ACT Conference, Seattle, WA, Aug. 1994 NASA CP 3294, Vol. 1, Pt 2, pp. 913-934. 
7. Jegley, D., Velicki, A., and Hansen, D., Structural Efficiency of Stitched Rod-stiffened Composite Panels with Stiffener Crippling," Presented at the 49th AIAA Structures, Structural Dynamics, and Materials Conference, Schaumburg, IL, April 2008.

8. Jegley, D., "Analysis of Selected Compression Splice Joint Locations in a Graphite-Epoxy Transport Wing Stub Box," NASA TM 110170, October 1995.

9. Hinrichs, S., Kropp, Y., and Jegley, D., "Analysis and Testing of Stitched/RFI Subcomponents," Sixth NASA/DOD Advanced Composites Technology Conference. Presented at the 6th ACT Conference, Anaheim, CA, August 1995, NASA CP-3326, Vol. 1, Part 1, 1996, pp. 209-231.

10. Lovejoy, A., "Finite Element Analysis of a Composite Semi-Span Test Article With and Without Discrete Damage," NASA CR 2000-210308, Aug. 2000.

11. Jegley, D., "Behavior of Compression-Loaded Panels with Stringer Terminations and Impact Damage," Journal of Aircraft. Vol. 35, No. 12, pp.942-948, Nov.-Dec., 1998.

12. Ambur, D., and McGowan, D., "Response of Composites Plates with Inclined Elliptical Notches and Subjected to Axial Compression," Presented at the 40th AIAA Structures, Structural Dynamics, and Materials Conference, paper Number AIAA-99-1276, St. Louis, MO, April 1999.

13. McGowan, D., Ambur, D., Hanna, T., and McNeill, S., "Evaluation of the Compressive Response of Notched Composite Panels using a Full-Field Displacement Measurement System," Presented at the 40th AIAA Structures, Structural Dynamics, and Materials Conference, paper Number AIAA-99-1276, St. Louis, MO, April 1999.

14. Jegley, D., Bush, H., and Lovejoy, A., "Evaluation of the Structural Response and Failure of a Full Scale Stitched Graphite-Epoxy Wing," Journal of Aircraft, Vol. 40, No. 6, pp. 880-886, November-December, 2003.

15. Jegley, D., "Structural Efficiency of Stitched Composite Panels with Stiffener Crippling." Journal of Aircraft, Vol. 42, No. 5, pp. 1273-1280, September-October, 2005.

16. Jegley, D., "Improving Strength of Post-Buckled Panels Through Stitching" Journal of Composite Structures. Vol. 80, pp 298-306. 2007.

17. Jegley, D., "The Influence Of Restraint Systems on Panel Behavior," presented at Society of Experimental Mechanics Conference, Mohegan Sun, Uncasville, Conn., June 2011.

18. Jegley, D., "Structural Efficiency and Behavior of Pristine and Notched Stitched Structure," presented at SAMPE Fall Technical Conference, Fort Worth. TX, Oct. 2011.

19. Jegley, D., "Failure at Frame-Stringer Intersections in PRSEUS Panels," American Society for Composites 27th Technical Conference, Arlington, TX, Oct. 2012.

20. Jegley, D., "Behavior of Frame-Stiffened Composite Panels with Damage," Presented at the 54th AIAA Structures, Structural Dynamics, and Materials Conference, paper Number AIAA-2013-1738, Boston, MA, April 2013. 